\title{
Envisaging the Role of Residents as Teachers in the Training of Medical Undergraduate Students
}

\author{
Saurabh RamBihariLal Shrivastava ${ }^{1}$, Prateek Saurabh Shrivastava ${ }^{2}$ \\ ${ }^{1}$ Medical Education Unit Coordinator and Member of the Institute Research Council, Department of Community Medicine, \\ Shri Sathya Sai Medical College and Research Institute, Sri Balaji Vidyapeeth - Deemed to be University, Ammapettai, \\ Nellikuppam, Chengalpet District, Tamil Nadu, India; ${ }^{2}$ Department of Community Medicine, Shri Sathya Sai Medical \\ College and Research Institute, Sri Balaji Vidyapeeth - Deemed to be University, Ammapettai, Nellikuppam, \\ Chengalpet District, Tamil Nadu, India
}

\section{INTRODUCTION}

The ideal way to improve the competence level of medical students is via teaching them and giving adequate exposure to the various clinical and ethical scenarios and supporting the same with reflection and constructive feedback. ${ }^{[1,2]}$ In the current era of medical education, where a teacher finds it difficult to maintain equilibrium between their primary role of teaching and patient care, there is a definite scope and adequate evidence which calls for the use of students as peer educators for the mutual benefit of both the learners and the student teacher. ${ }^{[1,3]}$ A near-peer teacher refers to those students who are senior to other trainees, nevertheless play an active role in teaching the junior students regardless of the fact that they are still not qualified content expert. ${ }^{[1-4]}$

\section{Residents as Teacher}

It is not something unusual that a postgraduate student, who work as a resident in their chosen specialty, has to fulfill multiple roles during the course of their training period. ${ }^{[2,3]}$ In other words, the residents act as teachers without being qualified as professional educators, and in the process continue their own process of learning and skill acquisition. ${ }^{[1,2,4]}$ Such form of near-peer learning is bound to happen as in most of the medical institutions, in contrast to the teacher, a medical student or intern spends more time with the department residents. It won't be wrong to document that residents tend to spend at least one-fourth of their time in teaching students about different clinical scenarios and gives immense importance to this role. ${ }^{[1-5]}$

As a matter of fact, as per the Dreyfus Model of skill acquisition, the attainment of level 5 of Master / Expert means that a student can teach others. ${ }^{[6]}$ Keeping this in mind, most of the regulatory bodies at the global level have incorporated that teaching and supervision of peers and students is one of the core competencies. ${ }^{[5]}$ It is a definite possibility that learners give more importance to the resident teaching as they are easily approachable (readily available and closer in age) than the teachers. In-fact, this also plays an important role in ensuring that the learner readily admits their mistakes and are more ready to accept the feedback, even if it is a negative one. ${ }^{[2,7]}$

As we move towards initiation of competencybased undergraduate curriculum, it becomes a necessity to strengthen its overall implementation. The component of residents-asteacher can be effectively utilized in the studentdoctor initiative of the newly introduced curriculum. The undergraduate students can be taught by the residents during their posting and this will not remain restricted to academic aspects, but even on the front of professionalism and the roles expected of a medical doctor by the society.

\section{Lessons from the field}

In a study done in the Indiana University School of Medicine, United States, the resident-asteacher curriculum was introduced for the benefit

CORRESPONDING AUTHOR: Dr. Saurabh RamBihariLal Shrivastava,MD Community Medicine, FAIMER, PGDHHM, DHRM, FCS, ACME. Professor, Department of Community Medicine, Shri Sathya Sai Medical College and Research Institute, Sri Balaji Vidyapeeth (SBV) - Deemed to be University, Thiruporur - Guduvancherry Main Road, Ammapettai, Nellikuppam, Chengalpet District - 603108, Tamil Nadu, India

E Mail ID: drshrishri2008@gmail.com

ARTICLE CYCLE: Received: 16/11/2020; Revised: 15/02/2021; Accepted: 24/03/2021; Published:30/06/2021

CITATION: Shrivastava SR, Shrivastava PS. Envisaging the Role of Residents as Teachers in the Training of Medical Undergraduate Students.J Comp Health. 2021;9(1):48-49. 
of family medicine residents. The study concluded that all first-year and third-year residents could provide feedback to other residents and even were well equipped to teach residents. ${ }^{[7]}$ On a similar note, the findings of systematic review and other studies have also envisaged the importance of resident-as-teacher program and its inclusion in curriculum in a systematic manner. ${ }^{[4,9,10]}$ At Shri Sathya Sai Medical College and Research Institute, a constituent unit of Sri Balaji Vidyapeeth, Puducherry, residents have been actively involved in clinical and practical undergraduate teaching.

\section{Benefits for different stakeholders}

The implementation of resident as a teacher program is beneficial for the residents (viz. improvement in confidence level, teaching skills, better organization of thoughts, feedback skills, mentoring role, better satisfaction, improved performance in exams, acquisition of leadership skills, and prepares them for future career, etc.), the learners (like in-depth understanding of the topic, better clinical skills, development of clinical thinking and reasoning, etc.), and also the institution (by creating an educational culture, formation of community of educators, attainment of learning outcomes by the students and improvement in the patient outcomes in the long run)..$^{[1,2,5,7-9]}$

\section{Identified challenges and potential solutions}

Although, there are multiple advantages attributed to the resident as a teacher program, most of the institutions lacks a formal and structured planning and implementation within their set-up. ${ }^{[2,5]}$ It is quite essential that residents should be trained about their role and the need to prepare for their teaching role, otherwise it becomes an ineffective teaching. This calls for the need to periodically assess the learners who are taught by residents to gauge the impact of the program. ${ }^{[2-7]}$ At the same time, residents should be explained about the significance of this practice and the benefits which they can derive out of the entire process, otherwise they will not enjoy the process, consider it as an additional workload and raise conflict with regard to their primary role of clinicians. ${ }^{[5]}$ All these areas should be carefully looked by the teachers and feedback in the form of surveys can be carried out to gain insights about the program and ways to improve it to enhance the overall effectiveness. ${ }^{[3-6]}$

\section{CONCLUSION}

In conclusion, postgraduate residents around the world teach their peers or junior students formally or informally, but more often than not they are not trained adequately to discharge this role. The need of the hour is to prepare them for this role and it is quite satisfying to note that the role of the resident as a teacher does not limit only to academic things, and they do play an important role of mentor, advisor, coach, role model and someone who can expedite the learning.

\section{REFERENCES}

1. Menezes A, Burgess A, Clarke AJ, Mellis C. Peerassisted learning in medical school: tutees' perspective. Adv Med Educ Pract 2016;7:31-8.

2. Gostelow N, Soothill G, Vawda S, Annan D. Near peerassisted learning to improve confidence for medical students' situational judgment tests. Educ Health (Abingdon) 2017;30:215-22.

3. Snell L. The resident-as-teacher: It's more than just about student learning. J Grad Med Educ 2011;3:4401.

4. Jain $P$, Rogers $R$, Stark R. Validity and applicability of consensus guidelines for resident-as-teacher programs. J Grad Med Educ 2019;11:617.

5. Ramani S, Mann K, Taylor D, Thampy H. Residents as teachers: Near peer learning in clinical work settings: AMEE Guide No. 106. Med Teach 2016;38:642-55.

6. Dreyfus SE. The five-stage model of adult skill acquisition. Bulletin of Science, Technology \& Society $2004 ; 24: 177$.

7. Aba Alkhail B. Near-peer-assisted learning (NPAL) in undergraduate medical students and their perception of having medical interns as their near peer teacher. Med Teach 2015;37:S33-9.

8. Hoffman LA, Furman DT Jr, Waterson Z, Henriksen B. A novel resident-as-teacher curriculum to improve residents' integration into the clinic. PRiMER 2019;3:9.

9. Hill AG, Yu TC, Barrow M, Hattie J. A systematic review of resident-as-teacher programmes. Med Educ 2009;43:1129-40.

10. Al Achkar M, Davies MK, Busha ME, Oh RC. Residentas-teacher in family medicine: a CERA survey. Fam Med 2015;47:452-8. 